\title{
Aldrin Epoxidase Activity in Developing Rabbit Lung
}

\author{
H. M. MEHENDALE ${ }^{(27)}$ \\ Department of Pharmacology and Toxicology, University of Mississippi Medical Center, Jackson, Mississippi, USA
}

\section{Summary}

Pulmonary aldrin epoxidase activity was determined in 2-, 4 , 6-, 8-, 12-, and 16-week-old male rabbits using isolated perfused lung preparations and in vitro incubation techniques. In the perfusion experiments, it was determined that aldrin epoxidase activity increased with age up to 12 weeks of age. Although there was an increase in the weight of lungs with age, this did not appear to be related to the increase in aldrin epoxidation. In vitro experiments carried out using the same substrate to tissue ratio failed to exhibit an age-related increase in the aldrin epoxidase activity. Extrapolated values for aldrin epoxidation from in vitro experiments yielded much higher values than realized from perfusion experiments. Accessibility of the substrate to the enzymatic sites, saturation of the accessible enzyme system, and limiting availability of the cofactor necessary for the oxidative reaction remain as the possible mechanisms for the discrepancy between perfusion and in vitro incubation studies.

\section{Speculation}

Pulmonary aldrin epoxidase activity determined using isolated perfused lung preparations does not correlate with in vitro results obtained from incubations fortified with cofactors. However, the ratio of the two may become a useful predictive factor to obtain realistic contribution of an organ to the metabolism of xenobiotics.

Because of their direct contact with the environment, the lungs are constantly exposed to innumerable environmental pollutants. These agents, which are often detrimental, can gain entry into the lungs either through direct exposure by inhalation or indirectly through the vascular system. A number of xenobiotics have been reported to be accumulated by the lungs (21). Of these, halogenated compounds constitute a diverse group of man-made chemical agents which have wide and extensive industrial use and consequently a wide environmental distribution. Investigations of the mechanisms of uptake and disposition of halogenated xenobiotics by the lung have been infrequent. There are numerous halogenated solvents which exhibit hepatotoxicity (4) upon exposure of animals to their vapors, indicating their uptake and subsequent redistribution from the lung. Among the chlorinated compounds reported to be accumulated in the lungs are: chlorpromazine $(23,24)$, chlorcyclizine $(1,11)$, and chlorphentermine (14). Mechanisms of uptake, metabolism, and disposition of these and other chlorinated compounds by the lungs remain largely unexplored.

Interactions of epoxides (halogenated or nonhalogenated) with the lung are of particular interest. Many carcinogenic agents may be metabolized to epoxides. These epoxides are thought to be the carcinogenic forms of the carcinogens (6). In addition, epoxides have been found to act as mutagens $(3,8)$, to act as arylating agents that react with proteins and nucleic acids in vivo $(5,12)$, and to cause malignant transformations of tissue culture cells (5). An example of a known interaction of epoxides with the lung is the pulmonary necrosis caused by bromobenzene, epoxide metabolites of which bind readily in the lung (22).
The presence of eposidase activity in the lung tissue was indirectly suggested by a report of the formation of hydroxylated metabolites of polycyclic hydrocarbons (6). Formation of an unstable epoxide intermediate is assumed in the hydroxylation of the compounds containing two vicinal unsubstituted carbon atoms (10). The first direct demonstration of epoxidase activity in lung tissue was reported by Mehendale et al. (19).

Aldrin and its epoxide, dieldrin (Fig. 1), are chlorinated cyclodiene pesticides extensively used in the past as pesticide sprays. Using isolated perfused rabbit lung preparations (19), it was demonstrated that aldrin from perfusate can be accumulated in the lungs, where it is metabolized to its epoxide, dieldrin. This epoxide is in turn accumulated by the lungs. There are two distinct phases to aldrin accumulation in the lungs from the circulating perfusate (19). Although aldrin was readily metabolized to dieldrin by the isolated perfused lung, dieldrin itself was not metabolized further. In the liver, which is the primary site of aldrin metabolism, dieldrin is metabolized by epoxide hydrase to give two isomeric diols which are subsequently conjugated $(10,16)$. The lack of pulmonary dieldrin epoxide hydrase activity was consistent with other reports of undetectable levels of this enzyme activity in the lung tissue $(9,20)$, although epoxide hydrase has been detected in human and hamster lungs $(2,3,7)$.

The objective of this study was to determine the epoxidase activity in developing rabbit lungs using aldrin as a substrate. Aldrin epoxidase was measured utilizing (1) an isolated perfused lung model; and (2) in vitro incubation of subcellular preparations. The immediate objective was to determine the course of development of aldrin epoxidase activity in the lung. The second objective was to determine if the enzyme activity measured by in vitro incubations may be compared to data from intact lung perfusions.

\section{MATERIALS AND METHODS}

\section{ANIMALS}

Male New Zealand White rabbits were used for this study, in view of relevant background information available on pulmonary aldrin epoxidation in this strain of rabbits (18). Animals ranging from 2 to 16 weeks (adult) of age were used in these studies. Animals were maintained in the University of Mississippi Medical Center animal facilities until immediately prior to use.

\section{SUBCELLULAR PREPARATION AND INCUBATION PROCEDURE}

The procedure described by Matsubara et al. (15) was used for preparing the lung homogenates. Animals were anesthetized with pentobarbital sodium $(60 \mathrm{mg} / \mathrm{kg}$ IV) which was mixed with heparin $(1000 \mathrm{IU} / \mathrm{kg})$. Lungs were removed and perfuse washed with warm $(0.9 \% \mathrm{w} / \mathrm{v})$ saline to wash out blood and any free pentobarbital. They were then placed in the preparation medium $(0.154 \mathrm{M}$ $\mathrm{KCl}$ and $0.05 \mathrm{M}$ Tris- $\mathrm{HCl}$ buffer, $\mathrm{pH}$ 7.4). After excess connective tissue was removed, the lungs were placed in $(1: 4 \mathrm{w} / \mathrm{v})$ measured volume of buffer (0.154 M KCl:0.05 M Tris- $\mathrm{HCl}, \mathrm{pH} \mathrm{7.4)}$ and homogenized with a Teflon-glass type Potter-Elvehjem homogenizer. The homogenate was centrifuged at $400 \times g$ for $10 \mathrm{~min}$, and 


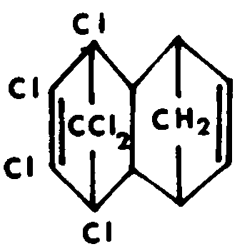

ALDRIN

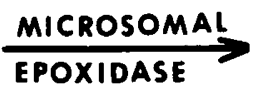

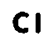

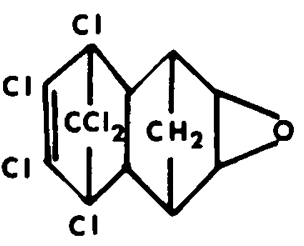

DIELDRIN
Fig. 1. Structures of aldrin and dieldrin.

the supernatant fluid was recentrifuged at $9000 \times g$ for $10 \mathrm{~min}$ to remove nuclear and heavy mitochondrial fractions, respectively. The $9000 \times g$ supernatant was used for incubation with aldrin. The reaction mixture contained $2.0 \mathrm{ml}$ Tris- $\mathrm{HCl}$ buffer $(0.05 \mathrm{M}$, pH 7.4), $1.0 \mathrm{ml}$ of enzyme, and $2 \mu$ moles of NADPH (or equivalent generating system). Reaction was initiated by the addition of 0.06 $\mu$ mole aldrin in $5 \mu$ l of ethanol. The amount of substrate used was $2.5 \mu$ moles $/ 10 \mathrm{~g}$ lung, which was found to be the saturation dose in a previous study (18). The reaction mixture was incubated in $25 \mathrm{ml}$ Erlenmeyer flasks at $37^{\circ} \mathrm{C}$ in a shaking bath for $30 \mathrm{~min}$. The reaction was terminated by adding $2 \mathrm{ml}$ of (9:1) hexane: acetone mixture.

\section{ISOLATED PERFUSED LUNG PREPARATIONS}

The perfusion apparatus was the same used previously in this laboratory $(18,19)$ and has been described in detail previously.

Animals were anesthetized with pentobarbital sodium $(60 \mathrm{mg} /$ $\mathrm{kg} \mathrm{IV)} \mathrm{which} \mathrm{was} \mathrm{mixed} \mathrm{with} \mathrm{heparin}(1000 \mathrm{IV} / \mathrm{kg})$. The trachea was exposed by a longitudinal ventral incision on the neck and clamped after the lungs were fully inflated. The diaphragm and the rib cage were incised exposing the heart and lungs, which were carefully removed intact. During cannulation, the tissues were bathed in warm physiologic saline. The pulmonary artery was cannulated with a 2-inch length of PE 360 tubing prefilled with the perfusate to avoid possible air emboli. The pulmonary vein was cannulated with 3-inch length of PE 360 tubing via an incision in the left ventricle. The trachea was cannulated with a 2-inch length of PE 330 tubing. The cannulated lung preparation was perfused with warm saline for approximately one min to remove the blood from the vascular system. The washed and blotted preparation was weighed along with the cannulae and the clamps. Weight of the lungs was obtained at the end of the experiment by weighing the lung preparation as above and by subtracting the weight of cannulae, clamp, etc., from the total weight. Cannulated lungs were connected to the preprimed apparatus, and perfusion was established through pulmonary artery along with artificial ventilation (18). Experiments were initiated after the initial equilibration period of $10 \mathrm{~min}$ by introducing $2.5 \mu$ moles aldrin per 10 $\mathrm{g}$ lung in $50 \mu \mathrm{l}$ of ethanol.

\section{EXTRACTION AND ANALYSES}

The reaction mixtures from the in vitro experiments, or the perfusate, and the lung homogenates from the perfusion experiments were extracted with (9:1) mixtures of pesticide quality hexane:acetone as described previously (18). Aldrin and dieldrin was analyzed by a gas-chromatograph fitted with an electron capture detector as previously described (17). Protein concentrations were determined using the biuret method or the method of Lowry et al. (13). Aldrin epoxidase activity was expressed as $\mu$ mole dieldrin formed per $\mathrm{mg}$ protein or per $\mathrm{g}$ lung tissue per $30 \mathrm{~min}$.

\section{RESULTS}

\section{PERFUSION EXPERIMENTS}

A time-course study was undertaken to determine the time of maximal production of dieldrin by isolated perfused rabbit lung preparations (Fig. 2). Lung preparations obtained from 12-weekold rabbits were utilized in this series of experiments. Experiments were initiated by the addition of $2.5 \mu$ moles of aldrin to $100 \mathrm{ml}$ perfusate and terminated at indicated time points. Aldrin and dieldrin concentrations were determined in perfusate and lung homogenate samples. Production of dieldrin by these lung preparations proceeded at a maximal rate during the first $15 \mathrm{~min}$, showed a curvilinear response between 15 and $30 \mathrm{~min}$, and appeared to level off thereafter (Fig. 2). Hence, all other experiments were terminated at $30 \mathrm{~min}$.

Figure 3 dipicts the pharmacokinetics of aldrin and dieldrin in a typical recirculating isolated perfused lung preparation. Aldrin is taken up by the lung in a biphasic manner: the concentration of aldrin initially decreases rapidly followed by a slower decline. Aldrin accumulated in the lung is metabolized to dieldrin, some of which appears in the perfusate. The concentration of dieldrin

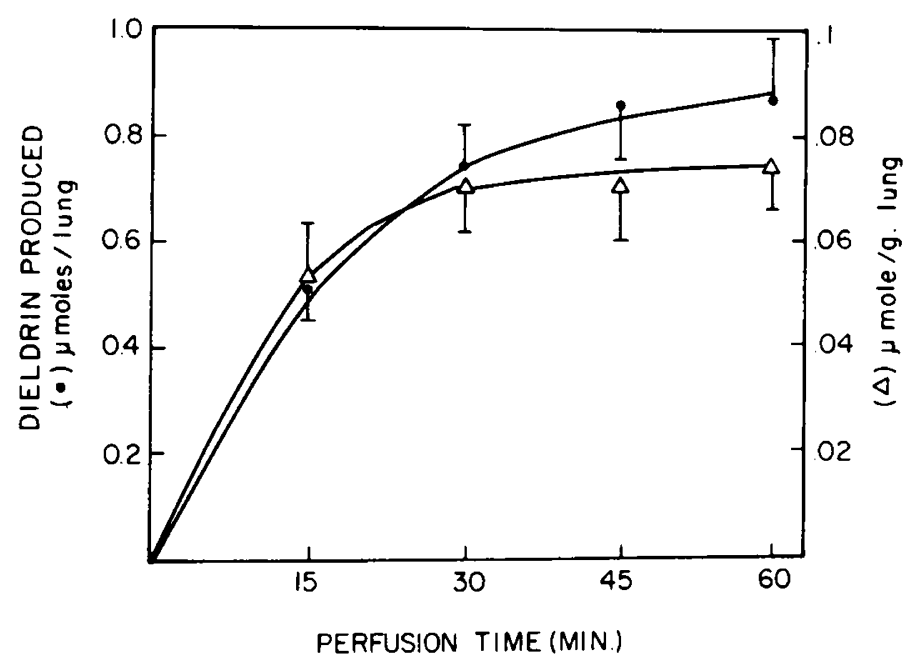

Fig. 2. Time-course of dieldrin formation by isolated perfused rabbit lung preparations. Total dieldrin produced by the lung preparations was determined by summation of dieldrin found in the perfusate and with lung homogenates in experiments terminated at indicated time points. Ordinate, dieldrin production either as $\mu$ moles per whole lung or as $\mu \mathrm{mole} / \mathrm{g}$ of lung tissue. Points, 3 to 5 individual determinations with 12-week-old rabbit lungs. Results are mean \pm S.E.

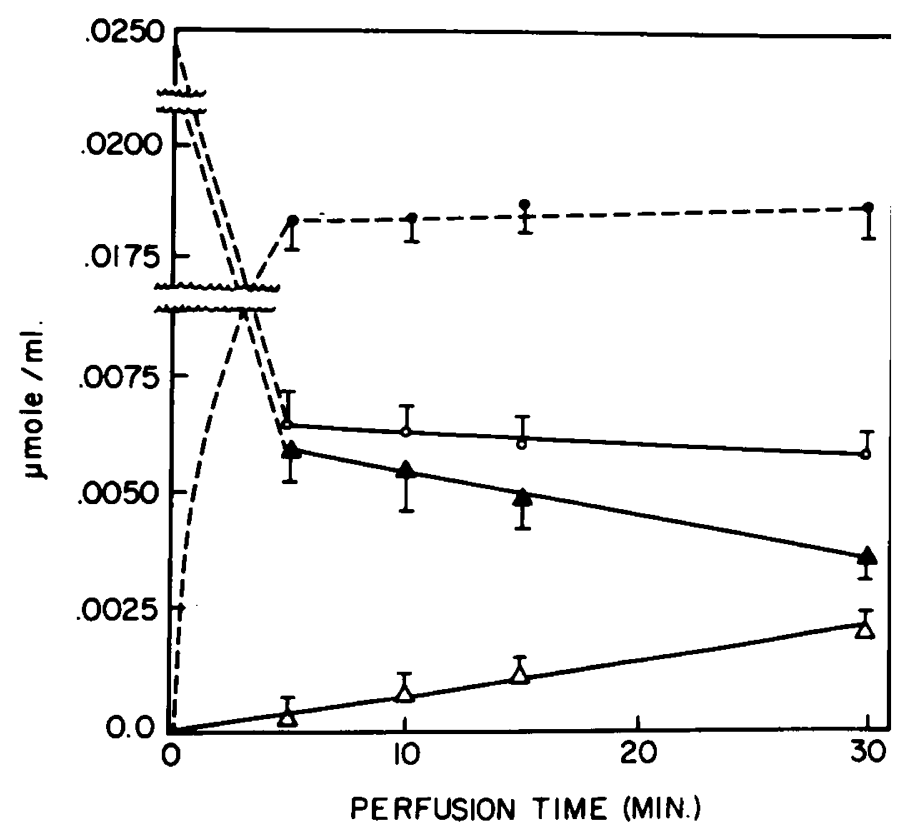

Fig. 3. Pharmacokinetics of aldrin in the perfusate. Aldrin and dieldrin were assayed in perfusate samples taken at indicated time points. Ordinate, $\mu$ moles of aldrin $(\Delta)$, dieldrin $(\Delta)$, or total aldrin equivalents $(O)$ per $\mathrm{ml}$ of perfusate; abscissa, time in min. Also shown in the graph is dieldrin (O) accumulation in the lung. The results presented are those obtained with 12-week-old rabbits. 


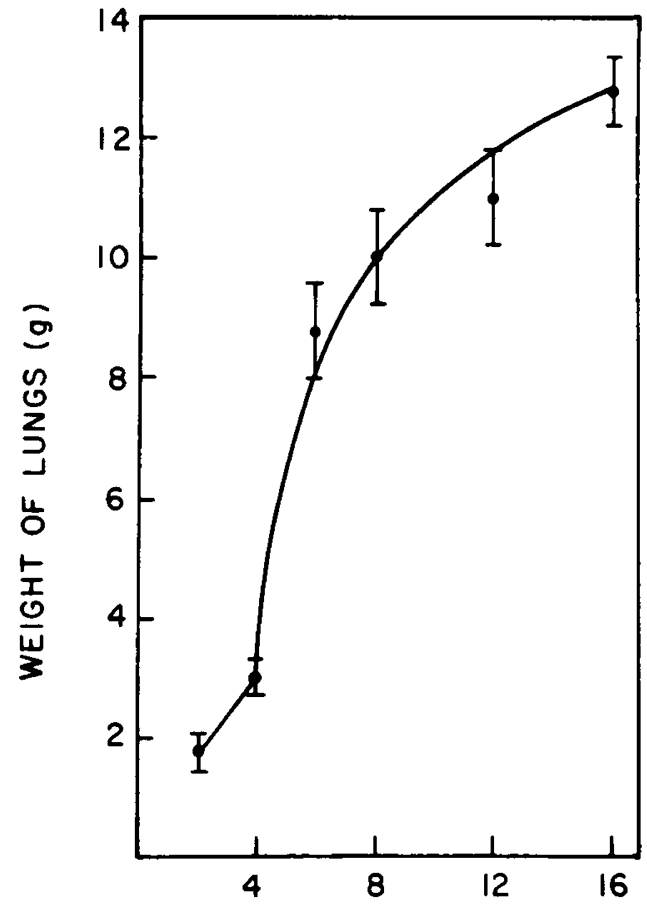

AGE OF RABBITS (WEEKS)

Fig. 4. Aldrin epoxidase activity in developing rabbit lungs. Aldrin epoxidase activity is expressed as $\mu$ moles of dieldrin produced by isolated perfused lung preparations per $g$ lung tissue per $30 \mathrm{~min}$ on the ordinate and the abscissa shows age of rabbits. Value at 2 weeks is significantly different from all other values except 4 week value. Four-week value is significantly different from all values except 2 and 16 week values. Sixweek value is significantly different from 12 -week value. $P<0.05$. Results are mean \pm S.E. of 3 to 5 individual determinations.

in the perfusate increases steadily throughout the duration of these experiments (Fig. 3). After the initial $10 \mathrm{~min}$, the curve representing the sum of aldrin and dieldrin in the perfusate levels off, suggesting that any aldrin taken up by the lung via the second phase of aldrin uptake is metabolized, and an equivalent quantity of dieldrin is returned to the perfusate. Total quantity of aldrin and dieldrin retained by the lung is represented by the dashed line in Figure 3. This also reached a steady-state after the initial 10 min.

Aldrin epoxidase activity of intact lung preparations obtained from 2- to 16-week-old rabbits was determined in similar perfusion experiments. Figure 4 illustrates the development of pulmonary aldrin epoxidase activity with age. Total dieldrin produced by the lung was calculated as the sum of dieldrin present in the perfusate and of that in the lungs at the end of 30 min perfusion. Aldrin epoxidase activity increased up to 12 weeks and appeared to decline slightly thereafter. Thus, lungs from 12-week-old rabbits exhibited maximal epoxidase activity. Weight of lungs also increased sharply between 4 and 8 weeks and increased at a much slower rate thereafter.

\section{IN VITRO EXPERIMENTS}

Aldrin was incubated with lung homogenates and various centrifugation fractions to determine the distribution of aldrin epoxidase activity (Table 1). Maximal activity was obtained in 9000 $\times g$ supernatant fraction. Hence, all in vitro experiments were conducted using $9000 \times g$ supernatant fraction of lung homogenates. In some experiments, the NADPH generating system was omitted to determine aldrin epoxidation in the absence of added cofactors. In the absence of added cofactor, only minimal production of dieldrin was observed $(0.017 \pm 0.002 \mu \mathrm{mole} / \mathrm{g} / 30 \mathrm{~min})$. Additional incubation experiments conducted with omission of the components of the NADPH generating system indicated that addition of NADP is essential to obtain any appreciable rates of aldrin epoxidation with $9000 \times g$ supernatant fractions. Additional experiments with lung homogenates have also indicated that addition of NADP is essential for the epoxidation of aldrin in intact lung (Mehendale, unpublished data).

Aldrin epoxidation was measured in vitro in preparations of $9000 \times g$ supernatant fractions of lungs obtained from male rabbits of age 2 to 16 weeks (Table 2). When the activity was expressed as $\mu$ moles/g of lung tissue, all lung preparations exhibited same level of activity with the exception of 6-week-old lung preparations which showed decreased activity. Incubations from 8- and 12-week-old lungs yielded the highest specific activity. In terms of the total potential of the lungs (Table 3), aldrin epoxidation increases with age by virtue of the increased lung

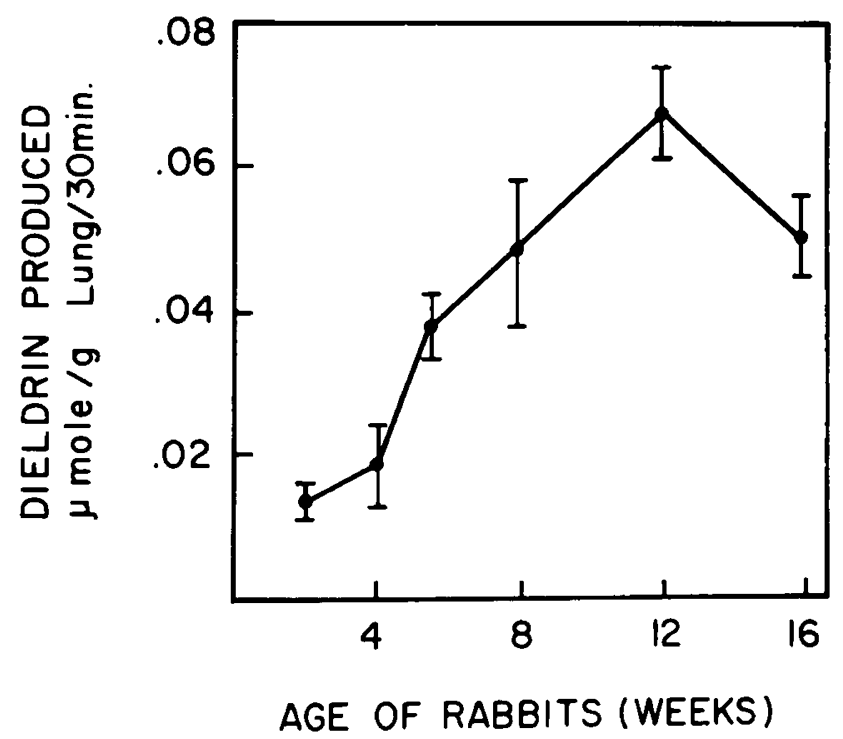

Fig. 5. Change in weight of lungs with age. Ordinate, wet weight of lungs in g; abscissa, age of rabbits. Results are mean \pm S.E. of 7 to 9 animals.

Table 1. Aldrin epoxidase activity in subcellular fractions of rabbit lung ${ }^{1}$

\begin{tabular}{lc}
\hline \multicolumn{1}{c}{ Lung fraction } & $\begin{array}{c}\text { Dieldrin produced } \\
(\mu \text { moles } / \mathrm{g} \text { lung } / 30 \mathrm{~min})\end{array}$ \\
\hline Homogenate & $0.174 \pm 0.001^{2}$ \\
$400 \times g$ pellet & $0.132 \pm 0.003$ \\
$400 \times g$ supernatant & $0.211 \pm 0.003$ \\
$9000 \times g$ pellet & $0.114 \pm 0.005$ \\
$9000 \times g$ supernatant & $0.205 \pm 0.003$ \\
\hline
\end{tabular}

${ }^{1}$ Aldrin epoxidase activity was determined in triplicate incubations of various centrifugation fractions obtained from 12-wk-old animals.

${ }^{2}$ Mean \pm S.E. of three determinations.

Table 2. Aldrin epoxidase activity in developing rabbit lung ${ }^{1}$

\begin{tabular}{ccc}
\hline & \multicolumn{2}{c}{ Dieldrin produced } \\
\cline { 2 - 3 } Age (wk) & $\mu$ moles/g lung/30 min & nmoles/mg protein/30 min \\
\hline 2 & $0.21 \pm 0.006^{2}$ & $2.80 \pm 0.20$ \\
4 & $0.18 \pm 0.008$ & $2.28 \pm 0.09$ \\
6 & $0.16 \pm 0.007^{3}$ & $2.35 \pm 0.33$ \\
8 & $0.18 \pm 0.009$ & $3.23 \pm 0.16$ \\
12 & $0.20 \pm 0.01$ & $3.12 \pm 0.36$ \\
16 & $0.18 \pm 0.015$ & $2.48 \pm 0.09$ \\
\hline
\end{tabular}

${ }^{1}$ Aldrin epoxidase activity was determined in $9000 \times g$ supernatant fractions of perfused-washed lungs. Incubation techniques are as described in the text.

${ }^{2}$ Mean \pm S.E. of at least 3 animals.

${ }^{3}$ Statistically different from all other values. $P<0.05$. 
Table 3. Aldrin epoxidation in rabbit lung

Aldrin epoxidase activity ( $\mu$ moles dieldrin/lung/30 min)

Age (wk)

Intact lungs, perfusion exper- In vitro experiments extrapoments ${ }^{1}$ lated $^{2}$

\begin{tabular}{rrr}
\hline 2 & $0.068 \pm 0.01^{3}$ & $0.49 \pm 0.06$ \\
4 & $0.081 \pm 0.01$ & $0.60 \pm 0.03$ \\
6 & $0.34 \pm 0.04$ & $1.39 \pm 0.22$ \\
8 & $0.38 \pm 0.01$ & $1.78 \pm 0.09$ \\
12 & $0.68 \pm 0.02$ & $2.17 \pm 0.25$ \\
16 & $0.62 \pm 0.05$ & $2.30 \pm 0.24$ \\
\hline
\end{tabular}

${ }^{1}$ Aldrin epoxidase activity was determined in isolated perfused lung preparations as described in the text. Total dieldrin produced was calculated by adding the quantity of dieldrin present in the perfusate and in the lung at the termination of the experiments.

${ }^{2}$ Amount of dieldrin formed in in vitro incubations as in Table 1 was equivalent to dieldrin production for $250 \mathrm{mg}$ of lung tissue. Total dieldrin per lung was calculated from the lung weight.

${ }^{3}$ Mean \pm S.E.

tissue reflected in increased wet weight of lungs with age (Fig. 5). The ratio of aldrin epoxidation measured by perfusion of whole lung to that measured by in vitro incubation was examined (Table 3). For 2- and 4-week lungs, the ratio is 7, whereas for other lungs it approximates 4 .

\section{DISCUSSION}

Results of the perfusion experiments indicate that pulmonary aldrin epoxidase activity increases with the age of rabbits. This does not appear to be a function of the wet weight of lung tissue because lung weight increased from 2 to 16 weeks of age. The results of perfusion studies cannot be corroborated by the in vitro experiments because age-related increase in aldrin epoxidase activity was not observed in in vitro incubation experiments. Often, results obtained from in vitro incubations of tissue preparations are extrapolated to the whole organ to assess the metabolism of a given chemical by the intact organ. In the present study, production of total dieldrin from aldrin by the intact perfused lung preparations can be calculated by the summation of dieldrin present in the perfusate and that present in the lung. Similarly, total dieldrin production by the whole organ can be calculated by extrapolation of the in vitro results. As may be noted in Table 3, the values derived at by two techniques are remarkably different. For 2- and 4-week-old lungs, there is a 7-fold difference, and for others, the factor appears to stay between 3 to 4 . The possibility of using such a factor to predict the in vivo activity is raised by these results. Alternatively, it may be more reliable to use intact, isolated perfused organs to assess the contribution of these organs toward the biotransformation of a particular xenobiotic.

In attempting to explain the reasons for the differences between the perfusion and the in vitro studies, two major factors may be considered. Firstly, transport of the substrate and accessibility to the enzyme may be different. Aldrin appears to be taken up by the pulmonary tissue by diffusion (18), and hence, the uptake process may not be limiting. However, compartmentalization of the substrate within the lung tissue may explain the inability of the perfused lung preparations to metabolize aldrin to dieldrin to the extent predicted by the in vitro studies. Saturation of the enzyme sites or limiting availability of cofactor may be expected to result in reduced epoxidation of aldrin. Although saturation of all the enzyme sites wtihin the lung seems unlikely, it is possible that the substrate may have easy access to only a portion of the enzyme sites, resulting in an apparent saturation of enzyme. On the other hand, availability of the cofactor may become limiting, hence, an apparent saturation of the epoxidase system. Recently, Thurman et al. (25) concluded that availability of cofactor can become limiting, thus affecting the rate of drug biotransformation reactions by intact perfused liver preparations. Whatever the mechanism, it is apparent that quantitative extrapolations of drug biotransformations from in vitro studies to in vivo situations may not be reliable.

\section{REFERENCES AND NOTES}

1. Anderson, M. W., Orton, T. C., Pickett, R. D., and Eling, T. E.: Accumulation of amines in the isolated perfused rabbit lung. J. Pharmacol. Exp. Ther., 189: 456 (1974).

2. Cohen, G., and Moore, B. O.: The metabolism of benzo(a)pyrene,7,8-dihydro7,8-dihydro-7,8-dihydroxybenzo(a)pyrene and 9,10-dihydro-9,10-dihydroxybenzo(a)pyrene by short term organ cultures of hamster lung. Biochem. Pharmacol., 26: 1481 (1977).

3. Cookson, M. J., Sims, P., and Grover, P. L.: Mutagenicity of epoxides of polycyclic hydrocarbons, Nature (Lond.), 234: 186 (1971).

4. Gehring, P. J.: Hepatotoxic potency of various hydrocarbon vapours relative to their narcotic and lethal potencies in mice. Toxicol. Appl. Pharmacol., 13: 187 (1968).

5. Grover, P. L., Forester, J. A., and Sims, P.: Reactivity of the K-region epoxides of some polycyclic hydrocarbons towards the nucleic acids and proteins of BHK 21 cells. Biochem. Pharmacol., 20: 1297 (1971).

6. Grover, P. L., Hewer, A., and Sims, P.: Metabolism of polycyclic hydrocarbons by rat lung preparations. Biochem. Pharmacol., 23: 323 (1974).

7. Harris, C. C., Autrup, H., Stoner, G., Yang, S. K., Lentz, J. C., Yelboin, H. U., Selkirk, J. K., Conner, R. J., Barrett, L. A., Jones, R. T., McDowell, E., and Trump, B. F.: Metabolism of benzo( $a)$ pyrene and 7,12-dibenz(a)anthracene in cultured human bronchus and pancreatic duct. Cancer Res., 37: 3349 (1977).

8. Huberman, E., Aspiras, L., Heidelberger, C., Groyer, P. L., and Sims, P.: Mutagenicity to mammalian cells of epoxides and other derivatives of polycyclic hydrocarbons. Proc. Natl. Acad. Sci. U. S. A., 68: 3195 (197!).

9. James, M., Bend, J. R., and Fouts, J. R.: Hepatic and extrahepatic metabolism of epoxides in the rabbit. Pharmacologist, 15: 191 (1973).

10. Jerina, D. W.: Chemical and biochemical factors which control the toxicity and carcinogenicity of arene oxides. In: Ts'o and Paolo: Chemical Carcinogenesis. p. 289 (Marcel Decker, New York, 1974).

11. Kuntzman, R., Klutch, A., Tsai, I., and Burns, J. J.: Physiological distribution and metabolic inactivation of chlorcyclizine and cyclizine. J. Pharmacol. Exp. Ther., 149: 29 (1965).

12. Kuroki, T., Huberman, E., Marquandt, H., Selkirk, J. K., Heidelberger, C., Grover, D. L., and Sims, P.: Binding of K-region epoxides and other derivatives by benz $(a)$ pyrene and dibenz(a)anthracene to DNA, RNA and proteins of transformable cells. Chem-Biol. Interact., 4: 389 (1972).

13. Lowry, O. H., Rosebrough, N. J., Farr, A. L., and Randall, R. J.: Protein measurement with the folin phenol reagent. J. Biol. Chem., 193: 165 (1951).

14. Lüllman, H., Rossen, E., and Seiler, K. U.: The pharmacokinetics of phentermine and chlorphentermine in chronically treated rats. J. Pharm. Pharmacol., 25: 239 (1973).

15. Matsubara, T., Prough, R. A., Burke, M. D., and Estabrook, R. W.: The preparation of microsomal fractions of rodent respiratory tract and their characterization. Cancer Res., 34: 2196 (1974).

16. Matthews, H. B., and McKinney, J. D.: Dieldrin metabolism to cis-dihydroaldrin diol and epimorization of cis to trans-dihydroaldrin diol by rat liver microsomes. Drug. Metab. Dispos., 2: 333 (1974)

17. McKinney, J. D., and Mehendale, H. M.: Formation of polar metabolites from aldrin by pea and bean root preparations. J. Agric. Food Chem., 21: 1079 (1973).

18. Mehendale, H. M., and El-Bassiouni, E. A.: Uptake and disposition of aldrin and dieldrin by isolated perfused rabbit lung. Drug Metab. Dispos., 3: 543 (1975).

19. Mehendale, H. M., El-Bassiouni, E. A., and McKinney, J. D.: Disposition of aldrin by isolated perfused rabbit lung preparations. Proc. Fed. Am. Soc. Exp. Biol., 33: 534 (1974).

20. Oesch, F.: Mammalian epoxide hydrase:inducible enzymes catalyzing the inactivation of carcinogenic and cytotoxic metabolites derived from aromatic and olefinic compounds. Xenobiotica, 3: 305 (1970).

21. Orton, T. C., Anderson, M. W., Pickett, R. D., Eling, T. C., and Fouts, J. R.: Xenobiotic accumulation and metabolism by isolated perfused rabbit lung. $J$. Pharmacol. Exp. Ther., 186: 482 (1973).

22. Reid, W. D., Ilet, K. F., Glick, J. M., and Krishna, G.: Metabolism and binding of aromatic hydrocarbons in the lung. Am. Rev. Respir. Dis., 197: 539 (1973).

23. Salzman, N. P. and Brodie, B. B.: Physiological disposition and fate of chlorpro mazine and a method for its estimation in biological material. J. Pharmacol. Exp. Ther., 118: 46 (1956)

24. Sjostrand, S. E., Cassaro, G. B., and Hangen, E.: Distribution of ${ }^{36}$ S-chlorpromazine in mice studied by whole body radioautography. Arch. Int. Pharma codyn. Ther., 156: 34 (1965).

25. Thurman, R. G., Marazzo, D. P., Jones, L. S., and Kauffman, F. C.: The continuous kinetic determination of p-nitroanisole o-demethylation in hemoglobin-free perfused rat liver. J. Pharmacol. Exp. Ther., 201: 498 (1977).

26. Preliminary results of these studies were presented at the 17th Annual meeting of the Society of Toxicology at San Francisco, California, 1978.

27. Requests for reprints should be addressed to: Dr. H. M. Mehendale, Departmen of Pharmacology and Toxicology, University of Mississippi Medical Center 2500 North State Street, Jackson, Mississippi 39216 (USA).

28. This research was supported by a grant from the Mississippi Lung Associatior Research and Medical Education Fund.

29. Received for publication May 15, 1979.

30. Accepted for publication June 13, 1979. 